\title{
ROYAL ACADEMY OF MEDICINE IN IRELAND.
}

\author{
President-EdWard H. Bennetr, M.D., F.R.C.S.I. \\ General Secretary-JoHN B. STORY, M.B., F.R.C.S.I.
}

\author{
SECTION OF OBSTETRICS. \\ President-F. W. KIDD, M.D. \\ Sectional Secretary-J. H. GLENN, M.D. \\ Friday, March 18, 1898. \\ The President in the Chair.
}

Specimens.

DR. SMrty showed a uterns, weighing 91 lbs., which be had remored for myoma by panhysterectomy. The patient did not complain of any symptoms, but the large tumour, which was uninodular, was in process of enucleation, and a portion of it was protruding through the os uteri, which was dilated to the size of a crown piece. The patient, who had been operated upon three weeks previously, was makitg an excellent recovery.

He also showed a aterus removed from a patient aged forty-nine. She was a widow, who supported herself and family by farming, but had latterly been unable to work, owing chiefly to pain in her back. The uterus was found retroflexed and adherent. The posterior cul-de-sac was opened, and the adhesions partly broken down with the finger, partly divided with scissors. An anterior colpotomy was then performed with a view to vaginal fixation of the uterus, but the hæmorrhage from the divided adhesions was so considerable that it was deemed safer to remove the uterus. Upon examination after removal the organ was found in a state of retroflexion, owing to a hard inflammatory band on its posterior surface, so that had the uterus been fixed in anteversion the constant strain upon this band would doubtless have caused such suffering that her symptoms would have been greatly aggravated. She is now perfectly well, and free from pain.

Dr. J. H. GLENN-Myomatous uterus removed by intraperitoneal hysterectomy.

Dr. R. D. Pureroy-Double ovarian cysts. 
Dr. JelLetr-Early specimen of sarcomatous ovary removed bog anterior colpotomp.

Clinical Report of the Rotunda, Hospital for three years, 1893-5.

Dr. W. J. Smrur read this Report. [It will be found in Vol. CV., at pages 29.5 and 383.$]$

The President said he was sure that the thanks of the Section were due to Dr. Smyly and his colloborators, Drs. Wilson and Jellett, for the Report. He thought that such results were not likely to be eclipsed for considerable time. He expressed surprise at the number of cases under the beading of aceidental bemorrhage. In 134 cases of abortion, 50 were curetted, which seemed to be a very large proportion. He congratulated Dr. Smyly ou there being no death from placenta prævia. He thought that severe post-partem hæmorrhage, not arising from the situation of the placenta at all, of ten occurred, and that its origin was often orerlooked. He thought that the case in which there was found a dotible uterus after removal of the uterus, and the subsequent recovery of this patient, was very remarkable.

DR. Kxorr asked how Dr. Smyly had prepared the saline solution used for transfusing.

DR. TweEdy congratulated Dr. Smyly on his results. He observed that a great many of the deaths were in women brought inte the hospital with death symptoms already marked. Three of the five septic cases had evidently become septic outside, and nothing could have saved them. The cases of eclampsia seemed to have been very severe. The giving of morphia in eclampsia was an interesting point. Some obervers say that its administration kills the child, but in case No. 7 of Dr. Smyly's the child was alive, although the mother got more morphia than any other case. He (Dr. Tweedy) said that morphia could not kill the child, but killed by acting on the respiratory centre. He noticed that laminaria tents had been used in one of the cases of death after abortion. Did thorough plugging of the ragina not dilate the cervix properly in this case?

Dr. LANe congratulated Dr. Smyly on the results of the three years. He could not quite agree with the President in saying that the deaths from accidental hxmorrhage were above the average.

Dr. Grems added his hearty congratulations to Dr. Smyly on the distinctly great improvement from former years, culminating in the wonderfully low death-rate. In reference to curetting in abortions he regarded that as distinetly an evolution. He thought that the use of the sharp curette in the treatment of abortions was, 
in skilled hands, quite safe, while for those not so self-confident the use of the blunt instrument was good practice. Dr. Smyly's three fatal cases of incomplete abortion would have died whether curetted or not. Fle thought that a serious omission in reference to forceps cases had been made in the Report-viz., there was no record of mortality in regard to the children. He thought that a record of these deaths should also be kept, as it would be of great interest to future generations.

Dr. Dorle considered eclampsia a form of uræmic convulsions. He had not had experience in the treatment of eclampsia with morphia, but had found chloral very useful. He thought that the condition of the kidneys should be found out at the time of the eclampsic convulsions. He concluded by congratulating $\mathrm{Dr}$. Smyly on bis results.

Dr. SmyLY, in reply, thanked the members for their kindly criticism. In compiling a Report of this kind accuracy was of the first impertance, and this he believed was secured by the system employed in the Rotunda. He believed that if the suggestions made by Br. Glenn were adopted by future reporters they would add to the value of future Reports. He would himself suggest that in addition to noting the total number of cases in which the temperature rose above $100.8^{\circ}$, it would be important to record the number of cases in which the patients were really ill, and those in which it rose on one occasion only. He agreed with Dr. Tweedy that one could not judge of the results of treatment from a small number of cases, and that even large numbers would give an erroneous view, as owing to the rule of the hospital admitting all cases when in labour, a large number were admitted in a condition in which treatment came too late. This was especially evident in the cases of eclampsia and septicæmia. Of the three deaths noted under the former heading, one was in a dying condition when admitted, and he did not believe that the other two could possibly have been saved, certainly not by chloroform.

The Section then adjourned. 